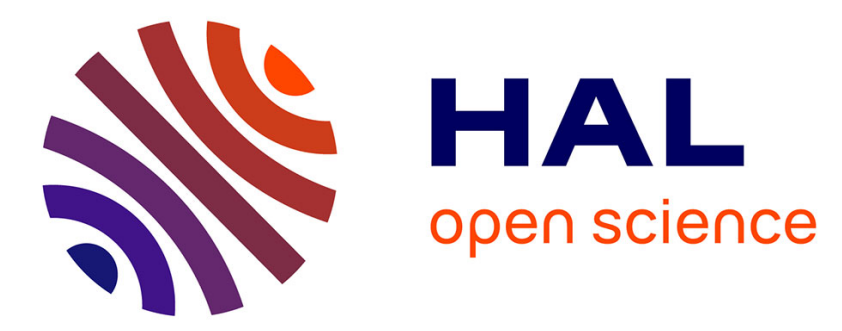

\title{
Pyroelectric control of the superprism effect in a lithium niobate photonic crystal in slow light configuration
}

M.-P. Bernal, J. Amet, J. Safioui, F. Devaux, M. Chauvet, J. Salvi, F.I. Baida

\section{To cite this version:}

M.-P. Bernal, J. Amet, J. Safioui, F. Devaux, M. Chauvet, et al.. Pyroelectric control of the superprism effect in a lithium niobate photonic crystal in slow light configuration. Applied Physics Letters, 2011, 98, pp.071101. 10.1063/1.3554373 . hal-00566921

\section{HAL Id: hal-00566921 \\ https://hal.science/hal-00566921}

Submitted on 6 May 2021

HAL is a multi-disciplinary open access archive for the deposit and dissemination of scientific research documents, whether they are published or not. The documents may come from teaching and research institutions in France or abroad, or from public or private research centers.
L'archive ouverte pluridisciplinaire HAL, est destinée au dépôt et à la diffusion de documents scientifiques de niveau recherche, publiés ou non, émanant des établissements d'enseignement et de recherche français ou étrangers, des laboratoires publics ou privés. 


\title{
Pyroelectric control of the superprism effect in a lithium niobate photonic crystal in slow light configuration
}

\author{
M.-P. Bernal, ${ }^{\text {a) }}$ J. Amet, J. Safioui, F. Devaux, M. Chauvet, J. Salvi, and F. I. Baida \\ Département d'Optique, Institut FEMTO-ST, UMR CNRS 6174, Université de Franche-Comté, \\ 25030 Besançon, France
}

(Received 6 December 2010; accepted 20 January 2011; published online 14 February 2011)

\begin{abstract}
In this letter, tunability of the beam deviation on a two dimensional lithium niobate photonic crystal superprism is experimentally demonstrated thanks to the pyroelectric effect. Since the superprism geometry has been designed in a slow light configuration, the observed pyroelectric beam steering tunability is considerably enhanced. A beam deviation of $3.4^{\circ} /{ }^{\circ} \mathrm{C}$ has been experimentally measured for a working wavelength of $1565 \mathrm{~nm}$. Direct applications can be found as ultracompact highly effective temperature variation sensors. (C) 2011 American Institute of Physics.

[doi:10.1063/1.3554373]
\end{abstract}

Photonic crystal (PC) superprisms are very promising devices for demultiplexing light beams. In most of PC superprisms reported in the literature beam steering is performed by a change in the light injection angle or in the input wavelength. ${ }^{1,2}$ A more versatile configuration consists of using a tunable $\mathrm{PC}$ which has been recently realized with a two dimensional (2D) lithium niobate (LN) superprism thanks to the electro-optic effect. ${ }^{3}$ There are few reports on temperature tunable PCs, and among them only one paper concerns the tunability of a superprism. ${ }^{4}$ A steering angle of $28^{\circ}$ is obtained for a temperature variation of $95 \mathrm{~K}$. Temperature tuning of the optical properties of PC cavities has been reported by Wild et al. ${ }^{5}$ More recently, Luo et al. ${ }^{6}$ showed temperature dependent lasing in a dye-doped 2D hexagonal polymer PC. The rest of the reported works demonstrate photonic band gap tunability. ${ }^{7-11}$

LN has been typically used for its acousto-optic, electrooptic, and nonlinear properties, but it also presents pyroelectric effect that has been somehow less exploited than the other phenomena. ${ }^{12}$ In this letter we use the LN pyroelectric effect in order to induce an internal field controlled by a moderate temperature change. Subsequently it induces a beam deviation due to the electro-optic effect. The pyroelectric effect provides a straightforward solution to check the electro-optic activity of the PC without the need of depositing electrodes. Furthermore, the pyroelectric effect shows an enhancement due to the fact of working on a slow light PC configuration; and, therefore, significant light deviation angles are observed with temperature variations of a few degrees Celsius. The pyroelectric effect has been known for 24 centuries-Theophrastus wrote the earliest known report, ${ }^{13}$ but it is only in the early $1970 \mathrm{~s}^{14}$ that applications of pyroelectric effect appeared. All ferroelectric crystals possess pyroelectric properties; this is the case of LN. In the last years, the pyroelectric effect in LN has been used for different applications such as microdomain reversal, ${ }^{15}$ electron emission, ${ }^{16}$ freestanding detectors, ${ }^{17}$ optical trapping of dielectric particles, ${ }^{18}$ and optical beam self-trapping. ${ }^{19}$

In this letter we report a pyroelectrically tunable PC device. As a typical configuration we experimentally demonstrate a pyroelectric PC superprism in which, for a wave-

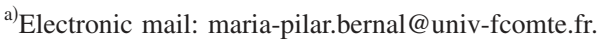

length of $1565 \mathrm{~nm}$, beam deviation is achieved by changing the substrate temperature. The measured effective pyroelectric effect is enhanced with respect to bulk LN because of the slow light propagation effect in PCs.

In a ferroelectric crystal at equilibrium, the net internal field inside the crystal is null since the field due to spontaneous polarization is compensated by free charges accumulated on polar faces. However, if the temperature changes, there is spontaneous polarization variation and, thus, an internal electric field $E_{p y}$ is created:

$$
E_{p y}=-\frac{1}{\varepsilon_{o} \varepsilon_{r}} p \Delta \mathrm{T},
$$

where $\varepsilon_{o}$ and $\varepsilon_{r}$ are the vacuum and relative dielectric constants, $\Delta \mathrm{T}$ is the temperature variation, and $p$ is the pyroelectric coefficient (for LN, $\varepsilon_{r}=28.7$ ). Below the Curie temperature $\mathrm{T}_{\mathrm{c}}\left(\sim 1200{ }^{\circ} \mathrm{C}\right) \mathrm{LN}$ is in a ferroelectric phase. It has a spontaneous polarization $\mathrm{P}_{s}$ parallel to the c-axis. $\mathrm{P}_{s}$ $=0.7 \mathrm{C} / \mathrm{m}^{2}$ at room temperature, which is compensated by charges with a surface charge density $\eta$ on the polar faces $\mathrm{c}^{+}$ and $\mathrm{c}^{-}$. This polarization charge density compensates the crystal polarization: $\left|\mathrm{P}_{s}\right|=|\eta|$. The spontaneous polarization changes induced by a temperature difference $\Delta \mathrm{T}$ are associated with a pyroelectric coefficient $p=-6 \times 10^{-5} \mathrm{C} \mathrm{m}^{-2} \mathrm{~K}^{-1}$ at $25^{\circ} \mathrm{C} .{ }^{18}$ According to Eq. (1) electric fields $E_{p y}$ as high as $10^{7} \mathrm{~V} / \mathrm{m}$ for a $4-5{ }^{\circ} \mathrm{C}$ temperature variation can take place, opposing the spontaneous polarization of $\mathrm{LN}^{20}$ Thanks to the pyroelectric effect, when $\mathrm{LN}$ is heated, a net positive electric field proportional to the temperature and oriented along the c-axis arises. The electric field is thus easily controlled with a moderate homogeneous temperature change of the medium and replaces advantageously a field formed with an external applied voltage. On the contrary, if lithium niobate is cooled down, a negative field is produced. In congruent LN, an internal pyroelectric field decay rate $\tau$ of about $8 \mathrm{~h}$ has been measured. ${ }^{19}$

In the present configuration we have fabricated a PC superprism on an X-cut LN wafer (Y propagation) (Fig. 1). The PC, an hexagonal array of air holes on a LN substrate $(r=86 \mathrm{~nm}, r / \mathrm{a}=0.2, \mathrm{a}=$ lattice period), has been fabricated with a focused ion beam (FIB) ${ }^{21}$ Vertical light confinement is guaranteed by fabricating the periodic lattice on an annealed proton exchange (APE) LN waveguide which in ad- 


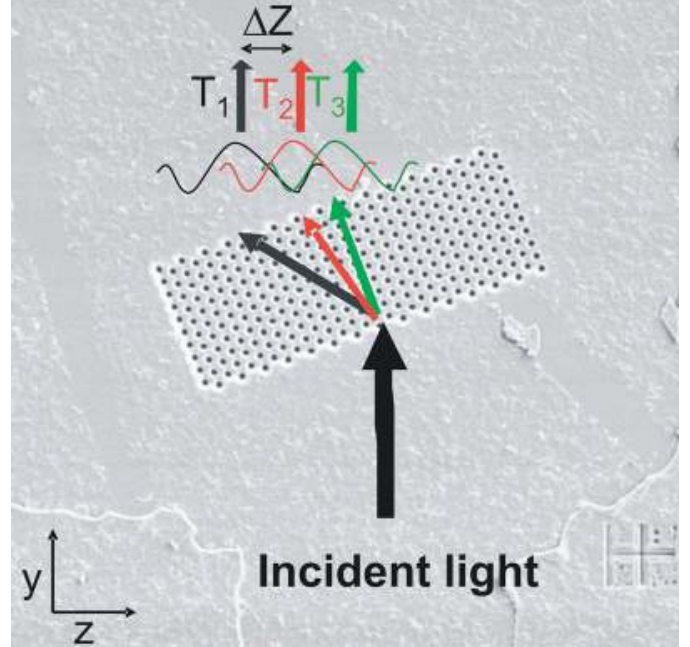

FIG. 1. (Color online) Scanning electron microscope image of the lithium niobate photonic crystal superprism. It was fabricated by FIB milling on an $\mathrm{X}$-cut Y-propagating annealed proton exchange waveguide. The internal generated field thanks to the pyrolectric field is parallel to the $\mathrm{Z}$-axis.

dition allows only propagation of transverse electric (TE) modes (electric field perpendicular to the hole axis). Therefore, for a light beam propagating along the Y-axis and with a linear polarization along the c-axis, the refractive index variation produced by electro-optic effect by the pyroelectric field is given by

$$
\Delta n=-0.5 n^{3} r_{33} E_{z},
$$

where $n$ is the effective index of the mode guided in an APE waveguide and takes the value of 2.143, $r_{33}$ is the electrooptic coefficient, and $E_{z}$ is the electric field component along the z-axis that is given by the pyroelectric effect $\left(E_{z}=E_{p y}\right)$.

If we introduce Eq. (1) into Eq. (2) we deduce the index of refraction change as a function of temperature variation due solely to the pyroelectric effect:

$$
\Delta n=\frac{0.5 n^{3} r_{33} p}{\varepsilon_{o} \varepsilon_{r}} \Delta \mathrm{T}
$$

In the case of bulk LN, Eq. (3) takes the form

$$
\Delta n=-3.7 \times 10^{-5} \Delta \mathrm{T} .
$$

Let us now observe experimentally if the PC properties can be tuned via the pyroelectric effect of LN. Furthermore, we want to compare the temperature variation needed to obtain an equivalent electro-optic response. In order to do that we have chosen to measure the steering angle of a LN PC superprism device in which the electro-optic tunability has been recently experimentally demonstrated. ${ }^{3}$

The PC geometry has been chosen so that it allows simultaneously ultrarefraction and slow light propagation. By ensuring slow light propagation, an electro-optic effect enhancement is obtained. The geometry presented in this work has been found by performing a systematic planar wave expansion numerical study. ${ }^{3}$

First, let us quantify the propagating optical mode shift at the exit of the photonic crystal in the electro-optic configuration (that is via the application of an external electric field). This measurement was performed with a scanning near field optical microscope (SNOM) apparatus in collection mode. Thanks to the SNOM measurements we have

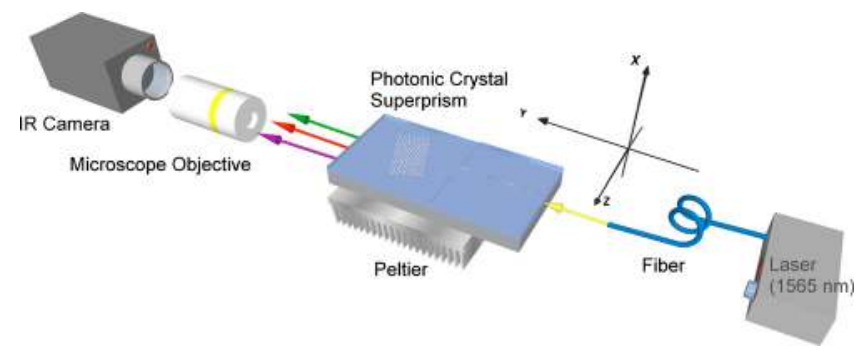

FIG. 2. (Color online) Experimental setup for the measurement of the pyroelectric beam steering tunability of a lithium niobate photonic crystal superprism.

been able to measure a beam waist of $3.8 \mu \mathrm{m}$. Under an external voltage of $100 \mathrm{~V}$, a beam shift $\Delta \mathrm{Z}$ of $1.833 \mu \mathrm{m}$ is measured corresponding to a refractive index change $\Delta n$ of $0.01{ }^{3}$

Let us now measure the beam deviation due to the pyroelectric effect at the exit of the superprism device as we modify its temperature in an open-circuit configuration. The experimental setup is shown in Fig. 2. In order to perform the experiment, the sample is placed between an insulating plastic cover and a metallic plate whose temperature is accurately controlled by a Peltier element, which guarantees homogeneous temperature throughout the sample with stability better than $0.1{ }^{\circ} \mathrm{C}$. Optical mode transmission is characterized by optical far field measurements. A tunable laser beam operating at $1565 \mathrm{~nm}$ is injected into the APE waveguide to excite the TE mode. The beam is refracted by the PC and propagates inside the waveguide before reaching the output waveguide facet that is subsequently imaged on an infrared camera as shown in Fig. 2.

Figure 3 shows the transmitted beam displacement at the exit of the PC as a function of the temperature. It presents an almost linear behavior. The measured beam translation at the APE waveguide exit is $\Delta \mathrm{Z}=0.8 \mu \mathrm{m}$ for a $\Delta \mathrm{T}=5{ }^{\circ} \mathrm{C}$. If we assume that the beam deviation is due to the internal field created by the pyroelectric effect, this beam deviation implies a refractive index change $\Delta n_{\mathrm{PC}_{-} \mathrm{Pyro}}=-4.36 \times 10^{-3}$. In Fig. 4 we have displayed cross-section images of the propa-

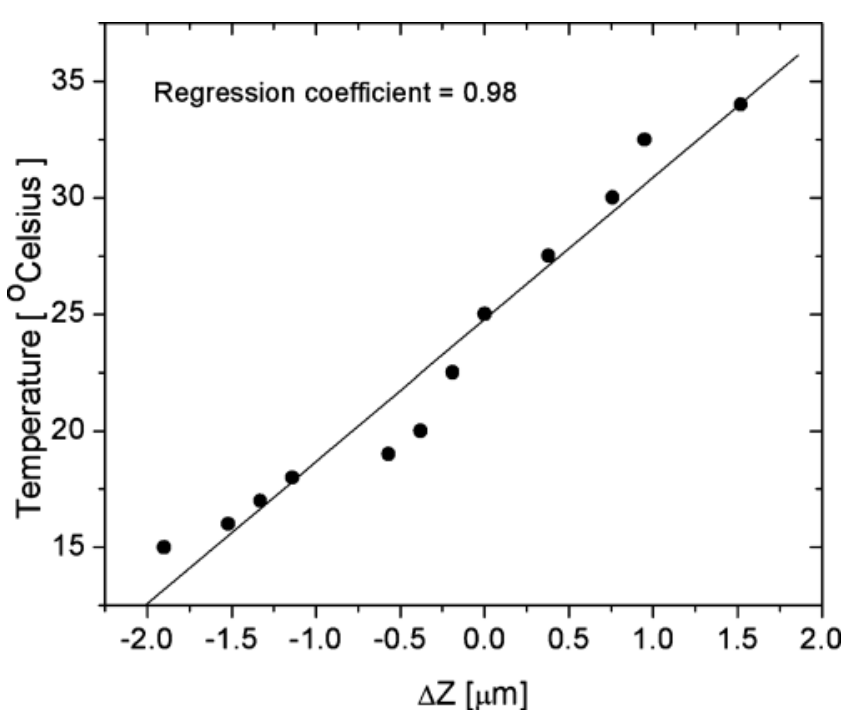

FIG. 3. Experimental beam position as a function of substrate temperature (circles) and the linear fit (solid line). 

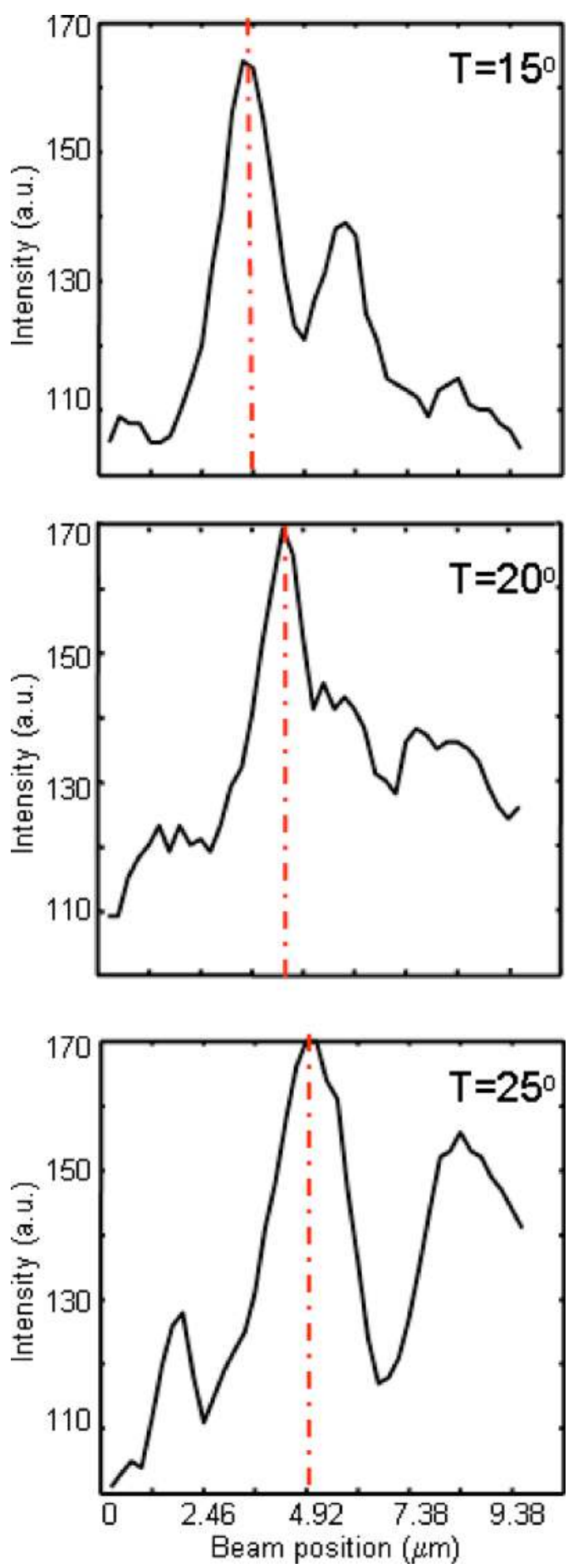

FIG. 4. (Color online) Optical mode $\mathrm{Z}$ cross-sections obtained at the exit of the APE waveguide for temperatures $\mathrm{T}=15,20$, and $25{ }^{\circ} \mathrm{C}$, respectively. We can easily appreciate the beam displacement due to the temperature variations.

gating mode at the exit of the PCs for 15,20 , and $25^{\circ} \mathrm{C}$ respectively.

If we apply Eq. (4), corresponding to bulk LN, the refractive index variation induced by a $5{ }^{\circ} \mathrm{C}$ temperature change is $\Delta n_{\text {Bulk Pyro }}=-1.85 \times 10^{-4}$. This value is far from the experimentally measured value. To explain this enhancement we have to take into account the enhancement of the electro-optic effect due to the PC geometry. Since we have designed the PC such that light at $1565 \mathrm{~nm}$ propagates in a slow light configuration, we can estimate the enhancement equation as $^{22}$

$$
\Delta n_{\text {PC_Pyro }}=\mathrm{f}^{3} \Delta n_{\text {Bulk_Pyro }},
$$

where $\mathrm{f}$ is the local field factor, which is inversely proportional to the group velocity inside the $\mathrm{PC}^{22}$ The predicted and experimental values of $\Delta n$ lead to a measured local field factor inside the photonic crystal of 2.85 , which is in good agreement with the local field factor obtained with the Pockels effect via the application of an excitation voltage of 0 to $-100 \mathrm{~V}(\mathrm{f}=2.35){ }^{3}$ It is important to note that the thermal variation of the refractive index given by the Sellmeier equation $^{23}$ is too weak to have any influence on the observed behavior. Moreover, this thermal variation is opposite in sign with the pyroelectric induced index change and would give an opposite beam displacement. In addition, this contribution is not enhanced by the PC contrary to the electro-optic effect. This fact allows us to compare the superprism effect via Pockels effect and via the pyroelectric effect. The internal generated field obtained by pyroelectric effect in a slow light configuration equivalent to an external applied voltage of $100 \mathrm{~V}$ has needed only $11^{\circ} \mathrm{C}$ of temperature variation. This observation demonstrates the thermal control via the pyroelectric effect of the beam deviation on a LN PC superprism of a size of $10 \times 4 \mu \mathrm{m}^{2}$, showing great potential in integrated optics, and opens the path to micrometric temperature variation sensors.

Authors are grateful to EU for financial support under Grant No. STREP 033297 3D-DEMO.

${ }^{1}$ H. Kosaka, T. Kawashima, A. Tomita, M. Notomi, T. Tamamura, T. Sato, and S. Kawakami, J. Lightwave Technol. 17, 2032 (1999).

${ }^{2}$ B. Momeni, M. Chamanzar, E. S. Hosseini, M. Askari, M. Soltani, and A. Adibi, Opt. Express 16, 14213 (2008).

${ }^{3}$ J. Amet, G. Ulliac, F. I. Baida, and M.-P. Bernal, Appl. Phys. Lett. 96, 103111 (2010).

${ }^{4}$ T.-H. Pei and Y.-T. Huang, Jpn. J. Appl. Phys., Part 2 46, L593 (2007).

${ }^{5}$ B. Wild, R. Ferrini, R. Houdré, M. Mulot, S. Anand, and C. J. M. Smith, Appl. Phys. Lett. 84, 846 (2004).

${ }^{6}$ D. Luo, X. W. Sun, H. T. Dai, H. V. Demir, H. Z. Yang, and W. Ji, J. Appl. Phys. 108, 013106 (2010).

${ }^{7}$ Ch. Schuller, F. Klopf, J. P. Reithmaier, M. Kamp, and A. Forchel, Appl. Phys. Lett. 82, 2767 (2003).

${ }^{8}$ J. Zhou, C. Q. Sun, K. Pita, Y. L. Lam, Y. Zhou, S. L. Ng, C. H. Kam, L. T. Li, and Z. L. Gui, Appl. Phys. Lett. 78, 661 (2001).

${ }^{9}$ B. Li, J. Zhou, R. Zong, M. Fu, and L. Li, J. Electroceram. 21, 711 (2008).

${ }^{10}$ S. W. Leonard, J. P. Mondia, H. M. van Driel, O. Toader, S. John, K. Busch, A. Birner, U. Gosele, and V. Lehmann, Phys. Rev. B 61, R2389 (2000).

${ }^{11}$ H. Takeda and K. Yoshino, Opt. Commun. 219, 177 (2003).

${ }^{12}$ B. Rosenblum, P. Braunlich, and J. P. Carrico, Appl. Phys. Lett. 25, 17 (1974).

${ }^{13}$ E. R. Caley and J. F. C. Richards, Theophrastus on Stones (The Ohio State University, Columbus, 1956).

${ }^{14}$ R. W. Whatmore, Rep. Prog. Phys. 49, 1335 (1986).

${ }^{15}$ D.-W. Kim, E. M. Bourim, S.-H. Jeong, and I. K. Yoo, Physica B 352 200 (2004).

${ }^{16}$ G. Rosenman, D. Shur, Ya. E. Krasik, and A. Dunaevsky, J. Appl. Phys. 88, 6109 (2000).

${ }^{17}$ J. H. Lehman, A. M. Radojevic, R. M. Osgood, Jr., M. Levy, and Ch. N. Pannel, Opt. Lett. 25, 1657 (2000).

${ }^{18}$ S. Grilli and P. Ferraro, Appl. Phys. Lett. 92, 232902 (2008).

${ }^{19}$ J. Safioui, F. Devaux, and M. Chauvet, Opt. Express 17, 22209 (2009).

${ }^{20}$ E. M. Avakian, K. G. Belabaev, A. A. Kaminskii, and V. K. H. Sarkisov, Phys. Status Solidi A 36, K25 (1976).

${ }^{21}$ F. Lacour, N. Courjal, M.-P. Bernal, A. Sabac, C. Bainier, and M. Spajer, Opt. Mater. 27, 1421 (2005).

${ }^{22}$ M. Roussey, F. I. Baida, and M.-P. Bernal, J. Opt. Soc. Am. B 24, 1416 (2007).

${ }^{23}$ T. R. Volk and M. Vöhleke, Ferroelectr. Rev. 1, 195 (1998). 